\title{
Seroconversión reversa y hepatitis B fulminante en paciente sometida a tratamiento quimioterápico por Linfoma no Hodgkin
}

\author{
Reverse seroconversion and fulminant hepatitis $B$ in a patient \\ undergoing chemotherapy for non Hodgkin Lymphoma
}

\author{
Milagros Bécares Lozano, Jorge González Román, Antonio Jiménez López \\ Servicio de Medicina Interna. Hospital Clínico Universitario de Salamanca. Sacyl. Salamanca
}

\begin{abstract}
Resumen
La pérdida de HBsAg en la hepatitis B aguda indica buen pronóstico, si bien el virus puede permanecer en el hígado con bajos niveles de DNA y $\mathrm{HBCAc}(+)$. El tratamiento inmunosupresor induce reactivación viral en estos pacientes, sobre todo el Rituximab y los corticoides, dando lugar a la reaparición de HBsAg en el llamado fenómeno de seroconversión reversa. Presentamos una paciente portadora de HBsAg (-), HBsAc (+) y HBcAc $(+)$, sometida a tratamiento inmunosupresor por presentar un LNH-B de células grandes. La ausencia de profilaxis con nucleósidos/nucleótidos precipitó la replicación de VHB con desarrollo de hepatitis aguda seguida de hepatitis fulminante y exitus. Se realiza revisión de la literatura al respecto.
\end{abstract}

Palabras clave: Inmunosupresores. Seroconversión reversa. Reactivación VHB. Linfoma No Hodgkin.

\section{Introducción}

La infección por virus de la hepatitis B (VHB) tiene una alta incidencia en nuestra sociedad. Aproximadamente 4.000 millones de personas son portadoras del $\mathrm{VHB}^{1}$, desde portador inactivo a hepatitis crónica progresiva con evolución a cirrosis hepática o hepatocarcinoma, siendo la causa del 5-10\% de los trasplantes hepáticos.

Dada la frecuente reactivación de esta enfermedad en los pacientes sometidos a tratamiento quimioterápico y/o inmunosupresor, pudiendo dar lugar a una hepatitis fulminante, la profilaxis con análogos de nucleósidos/nucleótidos es obligada en estos pacientes².

\section{Caso clínico}

Mujer de 79 años ingresada en el servicio de Medicina Interna de nuestro hospital en enero de 2011, diagnosticada de linfoma no Hodgkin-B (LNH-B) de células grandes, difuso estadio IV IPI-5. Debutó con fiebre y disnea. Descartadas causas infecciosas, enfermedades autoinmunes y tumores sólidos se practicó TAC toraco-abdominal con contraste que mostró adenopatías patológicas paratraqueales, hiliares y subcarinales (Figura 1), y afectación hepatoesplénica con áreas parcheadas hipodensas en lóbulo hepático derecho sugestivas de infiltración y bazo con mútiples imágenes nodulares focales hipodensas (Figura 2). La biopsia de un ganglio pararrenal izquierdo dio el diagnóstico anatomopatológico de LNH, siendo el BAS, PAAF transbronquial y biopsia hepática negativos. En el rastreo serológico de detectó HBsAg (-), HBSAc (+), $\mathrm{HBCAC}(+)$.

En febrero de 2011 ingresa en el servicio de Hematología iniciando tratamiento quimioterápico con 6 ciclos de Rituximab, Ciclofosfamida,

\section{Abstract}

Loss of HBsAg in acute Hepatitis B is a sign of good prognosis, though the virus can remain in the liver in the presence of $\mathrm{HBC} A c$ and low serum levels of HBV DNA. However immunosuppressive therapy can induce viral reactivation in these patients, mainly when rituximab and or corticosteroids are administered, with subsequent reappearance of $\mathrm{HBs} \mathrm{Ag}$ (reverse seroconversion).

We report a case of a female patient with a B-cell non Hodgkin lymphoma who at the onset of chemotherapy was negative for HBs Ag but positive for both HBs Ac and HBC Ac. Lack of prophylactic treatment with nucleotide/ nucleoside analogues allowed the development of acute HBV reactivation and fulminant hepatitis. A review of scientific literature is also included.

Key words: Immunosuppressants. Reverse seroconversion. HBV reactivation. Non-Hodgkin lymphoma

Adriamicina, Vincristina y Prednisona (R-CHOP). Esta última solo se administró durante el primer ciclo, ya que la paciente presentó una psicosis esteroidea, motivo por el que tuvo que suspenderse el fármaco. No recibió tratamiento profiláctico frente al VHB. Seis meses después de concluir los ciclos de quimioterapia, la paciente estaba en remisión completa, con TAC toraco-abdominal normal.

En abril de 2012 reingresa en el servicio de Medicina Interna aquejando astenia intensa con sensación nauseosa, acompañando importante ictericia de piel y mucosas, coluria y acolia de 3 días de evolución. No dolor abdominal, fiebre ni otros síntomas asociados. Estudio analítico: bilirrubina total (BT) 13,90 mg/dl a expensas de bilirrubina directa (BD), ALT $621 \mathrm{U} /$, AST $550 \mathrm{U} / \mathrm{l}$, actividad de protrombina (TP) 40\% como datos significativos. La ecografía abdominal descartó etiología obstructiva y los marcadores del VHB mostraron HBsAg (+), HBcAc (+) y DNA-VHB mayor de 100 millones de copias/ml (20 millones Ul/ml).

La evolución de la paciente fue tórpida con incremento progresivo de la ictericia (BT $30 \mathrm{mg} / \mathrm{dl}$. a expensas de BD), leve disminución de transminasas e hipoglucemia de $45 \mathrm{mg} / \mathrm{dl}$., con rápido desarrollo de encefalopatía hepática, ascitis, rectorragia con deterioro de la coagulación (disminución del TP hasta 15\%) y disminución de la albúmina, falleciendo 10 días después por fallo multiorgánico a pesar del inicio de tratamiento con Tenofovir.

\section{Discusión}

La hepatitis $B$ tiene una elevada prevalencia en pacientes con enfermedades hematológicas. El HBsAg se ha encontrado presente en el $22 \%$ de pacientes con LNH en población oriental $^{3}$. Sin embargo, estudios más recientes describen en el mismo tipo de población cifras inferiores de prevalencia, 
Figura 1. TAC torácico: adenopatías subcarinales, hiliares y paratraqueales

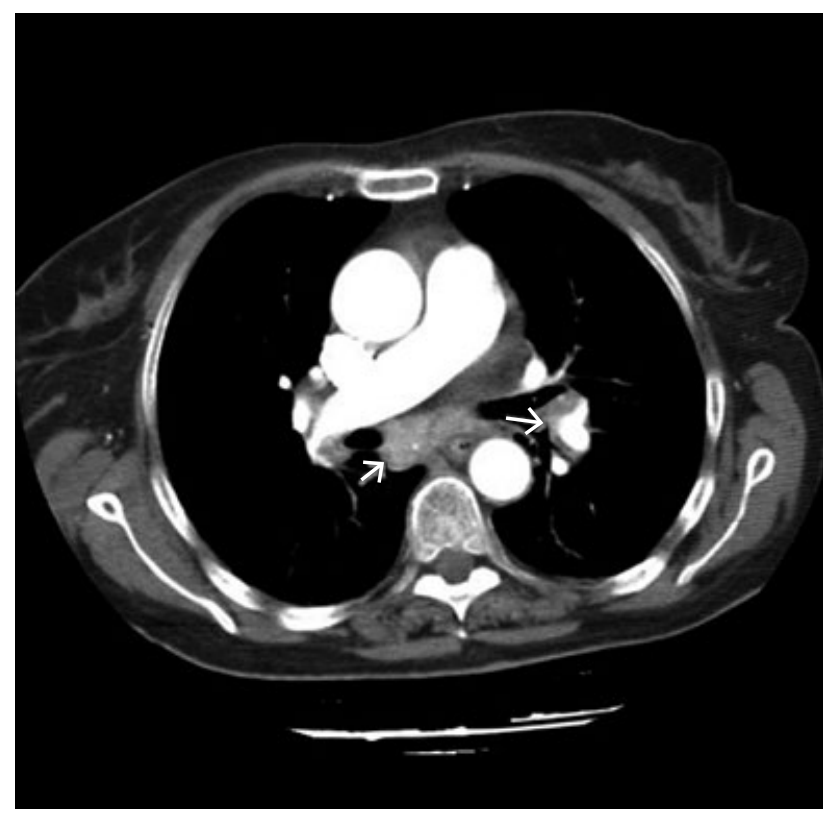

$16 \%{ }^{4}$, pudiendo variar en otros países dados los movimientos de población y las migraciones actuales.

Esta infección puede dar lugar a lesión hepática grave, llegando incluso en algunos casos a provocar hepatitis fulminante debido a la reactivación del virus ${ }^{5}$. Dado que la enfermedad puede ser asintomática durante mucho tiempo y producir complicaciones fatales se recomienda a todos los pacientes con riesgo de enfermedad crónica por VHB que vayan a ser sometidos a quimioterapia $y / 0$ tratamiento inmunosupresor realizar un screening previo con estudio serológico de VHB, ya que el DNA-VHB puede permanecer en el hepatocito durante muchos años después de haber sufrido la infección aguda ${ }^{6}$, aún siendo sus niveles en suero muy bajos 0 indetectables. Estas medidas deben tomarse, sobre todo, en pacientes varones mayores de 50 años con historia de HBV, enzimas hepáticos elevados y enfermedades hematológicas, especialmente linfomas ${ }^{2,4}$.

Nuestra paciente presentaba antes iniciar el tratamiento QT HBsAg (-), HBsAc (+), HbcAc (+), desarrollando tras la quimioterapia el fenómeno de "seroconversión reversa", con aparición de HBsAg (+) y presencia de HBcAc IgM (+) y DNAVHB mayor de 100 millones de copias, desarrollando así una hepatitis aguda con rápida evolución a hepatitis fulminante que la llevó al fallecimiento en pocos días. Se describe un caso similar al de nuestra paciente en mayo de 20097, si bien en este la reactivación ocurrió al mes de haber finalizado el tratamiento quimioterápico, falleciendo un mes más tarde, mientras que en nuestra paciente pasaron 10 meses hasta el desarrollo de la enfermedad aguda.

Los pacientes HBsAg (-) y HBCAc (+) sometidos a quimioterapia 0 agentes inmunosupresores sufren reactivación hasta en un $50 \%$ de los casos, dando lugar a elevación de ALT y de DNA-
Figura 2. TAC abdominal: Áreas parcheadas hipodensas en lóbulo hepático derecho. Esplenomegalia con imágenes nodulares hipodensas

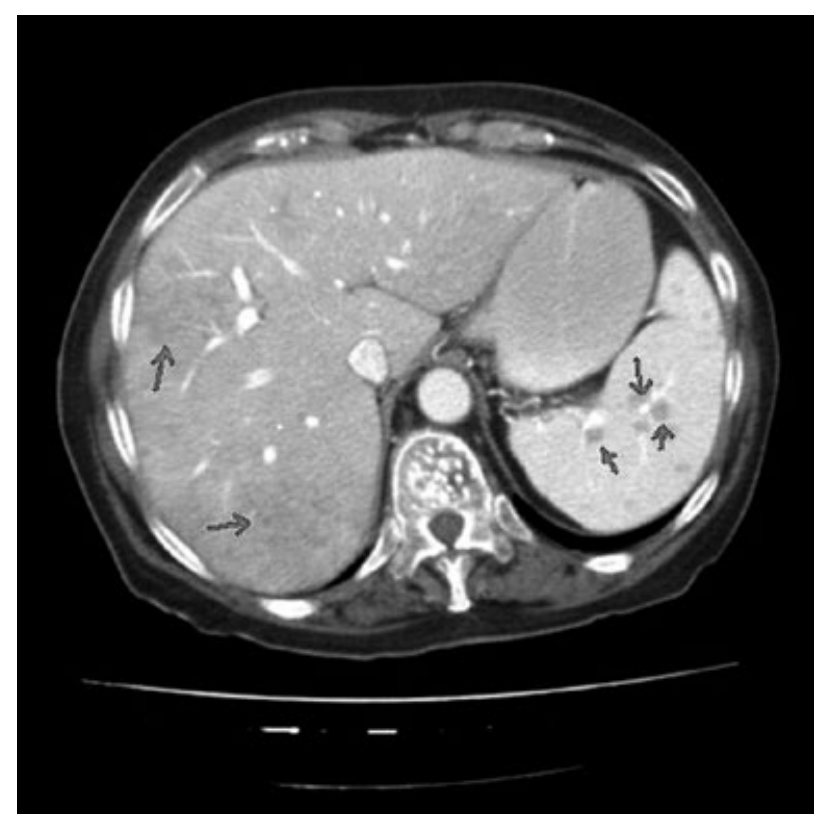

$\mathrm{VHB}^{8}$, siendo mayor esta incidencia en los $\mathrm{HBsAg}(+)$. Todos los candidatos a tratamientos inmunosupresores tienen un alto riesgo de reactivación de VHB, sobre todo con la toma de Rituximab ${ }^{9,10} \mathrm{y} / 0$ corticoides $^{11}$, ya que estos fármacos inducen por sí mismos la replicación viral, actuando sobre el genoma del virus. De acuerdo a las guías de la Sociedad Europea para el Estudio del Hígado (EASL 2012)², antes de iniciar la terapia inmunosupresora se debe determinar HBsAg y HBcAc. En los pacientes seronegativos se recomienda vacunación. Es conveniente intentar conseguir la normalización de ALT (una referencia sería la reducción de los niveles del enzima 1,25 veces por debajo de su límite superior de la normalidad)2 ${ }^{2}$. En los pacientes HBsAg (+) se deben determinar niveles de DNA y recibir profilaxis con análogos de nucleósidos/nucleótidos durante el tratamiento quimioterápico y hasta un año después de terminar el mismo, independientemente de los niveles de DNA. Si los niveles son inferiores a $2.000 \mathrm{Ul}$ y el tratamiento inmunosupresor será breve, se administrará Lamivudina ${ }^{12}$. Si los niveles son superiores a $2.000 \mathrm{UI} / \mathrm{ml}$. con tratamiento inmunosupresor prolongado o ciclos repetidos, se recomienda Tenofovir $^{13} 0$ Entecavir ${ }^{14}$ dado el riesgo elevado de resistencia a Lamivudina.

En los pacientes HBsAg (-) y HBCAc (+) realizar niveles de DNA-VHB y seguir la misma pauta de tratamiento profiláctico ya referida. Con el Entecavir se han descrito resistencias bajas, menor del $1 \%$ a los 4 años. Con el Tenofovir hasta la actualidad no se han encontrado resistencias y además ha mostrado mayor tasa de respuesta completa y mejoría histopatológica ${ }^{15}$. Una vez que la enfermedad se reactiva durante o después de la quimioterapia, a pesar del tratamiento con nucleósidos / nucleótidos el riesgo de mortalidad es muy alto, siendo la única opción terapéutica el trasplante hepático. 


\section{Bibliografía}

1. Ganem D, Prince AM. Hepatitis B virus infection-natural history and clinical consequences. N Engl J Med 2004; 350:1118-29.

2. European Association for the study of the liver. EASL Clinical Practice Guidelines management of chronic hepatitis B virus infection. J. Hepatol (2012). http://dx.doi. org/10.1016/j,jhep.2012.02.010

3. Liang RH, Lok AS, Lai CL.et al. Hepatitis B infection in patients with lymphomas. Hematol Oncol. 1990; 8:261-70.

4. 4. Wang Y, Luo XM, Yang D, et al. Testing for Hepatitis B infection in prospective chemotherapy patients: A Retrospective study. World JI Gastroenterol 2013; 19:923-30.

5. Firpi RJ, Nelson DR. Management of viral hepatitis in hematologic malignancies. Blood Rev 2008; 22:117-26

6. 6. Blackberg J, Kidd-Ljunggren K. Occult hepatitis virus after acute self-limited infection persisted for 30 years without sequence variation. J Hepatol .2000; 33:992-7.

7. Wu JM, Huang YH, Lee PC,Lin HC, Lee SC. Fatal reactivation of hepatitis B virus in a patient who was hepatitis $B$ surface antigen negative and core antibody positive before receiving chemotherapy for non-Hodgking lymphoma. J.Clin.Gastroenterol 2009; 43:496-8.

8. Kohrt HE, Ouyang DL, Keeffe EB. Antiviral prophylaxis for chemotherapy induced reactivation of chronic hepatitis B virus infection. Clin Liver Dis. 2007; 11:965-91.

9. Sarrecchia C, Cappelli A, Aiello P. HBV reactivation with fatal fulminating hepatitis during rituximab treatment in a subject negative for $\mathrm{HBsAg}$ and positive for $\mathrm{HBsAb}$ and HBCAb . J Infect Chemotherapy. 2005; 11:189-91

10. Evens AM, Jovanovic BD, SuYC, RaischDW, GangerD, BelknapSM, et al. Rituximab -associated hepatitis virus (HBV) reactivation in lymphoproliferative disease: metaanalysis and examination of FDA safety reports. AnnOncol 2011; 22:1170-80.

11. Tur-Kaspa R. Shaul Y, Moore DD, Burk RD, Okret S, Poellinger L, el al. The glucocorticoid receptor recognizes a specific nucleotide sequence in hepatitis B virus DNA causing increased activity of the HBV enhancer. Virology 1988; 167:630-3

12. 1 Hsu C, Hsiung CA, Su LJ, Wang WS, Wang MC, Lin SF ,et al. A revisit of prophylactic lamivudine for chemotherapy associated hepatitis $B$ reactivation in non-Hodgkin Iymphoma :a randomized trial. Hepatology 2008; 47:844-53

13. Marcellin P, Heathcote EJ, Corsa A, Liu Y, Miller MD, Kitrinos KM. No detectable resistance to tenofovir disoproxil fumarate (TDF) following up to 240 weeks of treatment in patients with $\mathrm{HBeAg}+$ and $\mathrm{HBeAg}$ - chronic hepatitis B virus infection. Hepatology $2011 ; 54: 480 A$.

14. Chang TT, Lai CL, Kew YS, Lee SS, Coelho HS, Carrilho FJ,et al. Entecavir treatment for up to 5 years in patients with hepatitis B e antigen-positive chronic hepatitis B. Hepatology 2010; 51:422-30.

15. Dienstag JL. Benefits and risks of nucleoside analog therapy for hepatitis B. Hepatology 2009; 49:S112-S21. 